\title{
Association of 11beta-hydroxysteroid dehydrogenase type 1 (HSD11B1) gene polymorphism with Type 2 Diabetes Mellitus in a sample Egyptian Population
}

Salah Hussein Elhalawany*1, Raef Malak Botros ${ }^{1}$, Eman Mohamed Fahmy ${ }^{2}$, Alaa Tarek Younis ${ }^{2}$, Laila Mahmoud Ali Hendawy ${ }^{1}$

${ }^{1}$ Department of internal Medicine, Endocrinology and Diabetes Unit, Faculty of Medicine, Ain Shams University, Cairo, Egypt

${ }^{2}$ Department of of Internal Medicine, Endocrinology and Diabetes Unit, Faculty of Medicine, Helwan University, Cairo, Egypt

*Corresponding Author: Salah Hussein Elhalawany, Mobile: 00201098127872, E-mail: salah.hussein@med.asu.du.eg

\begin{abstract}
Background: Recently, numerous studies have associated polymorphisms in 11 beta-hydroxysteroid dehydrogenase type 1 (HSD11 $\beta 1$ ) gene and T2DM risk. However, there is still a lack in the published literature evaluating the association between HSD11 $\beta 1$ gene polymorphism and the risk of T2DM.

Objective: The Aim of the study was to assess the association of HSD11ß1gene polymorphism (rs846910) with Type 2 diabetes mellitus (T2DM) in a sample of the Egyptian population.

Patients and methods: Our study was conducted on 100 subjects; their mean age was $50.26 \pm 9.1$ years old. They were selected from Diabetes Outpatient Clinics of our institution for 6 months in the period from June 2019 to December 2019. They were divided into two groups: 60 type 2 diabetic obese patients with BMI $>25 \mathrm{~kg} / \mathrm{m}^{2}$ (Group I) and 40 age- and sex-matched controls (Group II).

Results: There was no statistically significant difference between cases and controls in terms of HSD11ß1 polymorphism (rs846910). The regression analysis showed that the HSD11 $\beta 1$ polymorphism did not significantly increase the risk of diabetes mellitus (DM). Detection of HSD11 $\beta 1$ gene polymorphism in the study showed that homozygous GG genotype was more prevalent than GA genotype. However, there was no significant difference between GG and GA in terms of fasting and postprandial sugar and in terms of lipid profile.

Conclusion: The present study showed no significant association between HSD11 $\beta 1$ polymorphism (rs846910) and T2DM. Moreover, the HSD11 $\beta 1$ polymorphism (rs846910) is not correlated with glycemic status or lipid profile.
\end{abstract}

Keywords: HSD11B1 gene polymorphism, Single nucleotide polymorphism, T2DM, Obese.

\section{INTRODUCTION}

Diabetes mellitus is one of the fastest rising global health crises of the 21st century. In 2019, it is estimated that 463 million people have diabetes and this number is expected to reach 578 million by 2030 , and 700 million by 2045 . Egypt has been among the top ten countries for the number of people with DM with 8.9 million expected to project to 11.9 million in 2030. This carries a huge economic and social burden (1).

T2DM accounts for $90-95 \%$ of all diabetic population. The increased incidence of T2DM increases with age, obesity, and lack of physical activity. Obesity is the leading cause of insulin resistance, which is the fundamental risk factor for T2DM development ${ }^{(2)}$. While environmental factors could trigger the pathogenesis of T2DM, the development of T2DM is presumed to be largely genetically determined. The higher concordance rate for T2DM development in monozygotic twin pairs than dizygotic twins advocates the significant contribution of genetic factors ${ }^{(3)}$. To date, more than 50 genes have been studied for their T2DM susceptibility in various populations; a shred of rising evidence has linked polymorphisms in HSD11 131 gene and T2DM risk ${ }^{(4)}$.
Recently, evidence has linked polymorphisms in HSD11 $\beta 1$ gene and T2DM risk. HSD11 $\beta 1$ encodes 292 amino acid proteins. HSD11 $\beta 1$ enzyme produces active cortisol from inert cortisone, thus plays a prominent role in glucocorticoid action (5). Among many, Single Nucleotide Polymorphisms (SNPs) of the HSD11 $\beta 1$ gene, rs846910, in the 5' promoter region of the HSD1 $1 \beta 1$ gene, has been studied and the results showed a conflicting association with T2DM and metabolic syndrome in different populations ${ }^{(6)}$. However, there is still paucity in the published data that evaluates the association between HSD11 $\beta 1$ gene polymorphism and the risk of T2DM. Therefore, this study aimed to evaluate the association of HSD11ß1gene polymorphism (rs846910) with T2DM in a sample of Egyptian population.

\section{PATIENTS AND METHODS}

Our study was conducted on 100 subjects; their mean age was $50.26 \pm 9.1$ years old. They were selected from Diabetes Outpatient Clinics of our institution for 6 months in the period from June 2019 to December 2019. They were divided into two groups: 60 type 2 diabetic obese patients with $\mathrm{BMI}>$

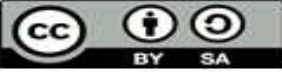

This article is an open access article distributed under the terms and conditions of the Creative Commons Attribution (CC BY-SA) license (http://creativecommons.org/licenses/by/4.0/) 
$25 \mathrm{~kg} / \mathrm{m}^{2}$ (Group I) and 40 age- and sex-matched controls (Group II).

\section{Ethical approval}

An approval of the study was obtained from Ain Shams University Academic and Ethical Committee. Informed consents were obtained from all participants included in our study.

All patients recruited in this study were subjected to full medical history, family history of DM, medication list (metformin, oral hypoglycemic drugs, insulin, and statins). All subjects were physically examined (Body Mass Index (BMI), waist circumference (WC), systolic, and diastolic blood pressure. Laboratory investigations included FBS, 2 hours post prandial blood glucose, HbA1c, lipid profile, Fasting s. insulin, HOMA-IR, and PCR for analysis of HSD11 $\beta 1$ gene (rs846910).

Exclusion criteria: Patients with chronic liver disease, acute or chronic kidney disease, type $1 \mathrm{DM}$, known cases of connective tissue disorder, malignancy and infections were excluded from our study.

Patient's demographics and medical history were obtained from the patient's file or during the patients visit. BMI was calculated using the standard formula [weight $(\mathrm{kg}) /$ height $\left(\mathrm{m}^{2}\right)$ ].

Whole blood samples were collected after an overnight fasting from all 100 subjects. Blood collected was split into three portions; the first portion was used to measure fasting blood glucose (FBG) and collected in $\mathrm{Na}$ fluoride-containing vacutainer tubes. The second portion was collected on EDTA containing vacutainer tubes to measure glycated hemoglobin (HbAlc \%). The third portion of blood was centrifuged to separate serum for the measurement of insulin and lipid profile (triglycerides (TG), total cholesterol (TC), low-density lipoprotein cholesterol (LDL-C), high-density lipoprotein cholesterol (HDLC)) and isolation of DNA and analysis for HSD11 $\beta 1$ (rs846910) gene polymorphism by real-time PCR technique. The homeostasis model assessment of insulin resistance (HOMA-IR) was calculated using the following equation: [fasting blood glucose $(\mathrm{mg} / \mathrm{dL})$ $\times$ fasting blood insulin $(\mu \mathrm{U} / \mathrm{mL}) / 405)$. All routine work analyses were measured on the same day of the blood collection, the remaining samples were stored at $-80^{\circ} \mathrm{C}$ till the time of assay for insulin and HSD1131(rs846910) gene polymorphism.

Isolation of DNA and analysis for HSD11 $\beta 1$ (rs846910) gene polymorphism was done by real-time PCR technique, which included:1) DNA Extraction by salting out method (DNA Quick reagents, Bio-serve.); 2) Amplification and allelic discrimination using TaqMan universal master mix II and ready-made TaqMan SNP genotyping assay for rs846910. TaqMan SNP genotyping assay for rs846910 contains sequence-specific forward and reverse primers to amplify the polymorphic sequence of interest.

DNA fragments containing the analyzed polymorphisms for rs846910 were amplified using the following primers and probes: F: 5'-CTC TGT TGC TTG TGC TTG ATT C-3', R: 5'-AGA GCA GGC TTT CAG CAG ATA C-3' and unlabeled probe: 5' CTGGTGGGAATGATCAAATCAGAGAGA-3'.

The PCR was initiated with a 10-min denaturation at $950{ }^{\circ} \mathrm{C}$. Thermal cycling (60 cycles) consisted of denaturation at $950{ }^{\circ} \mathrm{C}$ for $10 \mathrm{~s}$, then $10 \mathrm{~s}$ annealing with a touchdown protocol covering a range of annealing temperatures from $680{ }^{\circ} \mathrm{C}$ to $580{ }^{\circ} \mathrm{C}$ (decreasing $180{ }^{\circ} \mathrm{C}$ per cycle), and elongation at 720 ${ }^{\circ} \mathrm{C}$ for $10 \mathrm{~s}$. HRM acquisition and analysis After amplification, PCR products were denatured at $950{ }^{\circ} \mathrm{C}$ for $1 \mathrm{~min}$ and cooled $\left(2.50{ }^{\circ} \mathrm{C} / \mathrm{s}\right.$ to $\left.400{ }^{\circ} \mathrm{C}\right)$ to form heteroduplexes. High-Resolution Melting Analysis was performed by heating from $558^{\circ} \mathrm{C}$ to $900{ }^{\circ} \mathrm{C}$, with 25 acquisitions per $10^{\circ} \mathrm{C}^{(7)}$.

\section{Statistical analysis}

The collected data were revised, coded, tabulated, and introduced to a PC using Statistical Package for Social Science (SPSS 20). Data were presented and a suitable analysis was done according to the type of data obtained for each parameter. Descriptive statistics: Mean \pm Standard deviation (SD) for numerical data and Frequency and percentage of non-numerical data. Mann Whitney test for abnormally quantitative variables, to compare between two studied groups. Chi-square test for categorical variables, to compare between different groups. Correlation analysis (using Spearman's method) was used to assess the strength of association between two quantitative variables. The correlation coefficient (denoted symbolically "rs" for Spearman's correlation) defines the strength and direction of the linear relationship between two variables. Probability $(p) \leq 0.05$ was considered significant and $<0.01$ highly significant. Significant relations were graphically represented by pie and scatter graphs.

\section{RESULTS}

The current study showed significant differences between cases and controls as regards SPB, DBP, WC and BMI. Patients had significantly higher SBP, DBP, $\mathrm{WC}$, and BMI than the control group. Similarly, there were statistically significant differences between cases and controls regarding FBG, $2 \mathrm{hPP}$ and HbAlc $(\mathrm{p}<$ 0.01 ). Patients had significantly higher FBG, $2 \mathrm{hPP}$, and HbA1c than the control group (Table 1). In addition, there were statistically significant differences between cases and controls in terms of total cholesterol, triglycerides (TG), LDL-C, and HDL-C. Patients had significantly higher total cholesterol level, 
TG, and LDL-C than control group, while HDL-C was higher in control group ( $\mathrm{p}<0.01)$ as shown in table (1).

Regarding our primary outcome, there was no statistically significant difference between cases and controls in terms of HSD11 $\beta 1$ (rs846910) gene polymorphism $(\mathrm{p}=0.447)$ (Table 2$)$.

Also, the regression analysis showed that the HSD11ß1 (rs846910) polymorphism did not significantly increase the risk of diabetes mellitus (OR $1.724,95 \% \mathrm{CI}(0.601-4.94))$ as shown in table (3).
Moreover, there were no statistically significant differences between individuals with $G G$ and individuals with GA in terms of SPB, DBP, WC and BMI [ $(p>0.05)$ "Table 4"]. Similarly, there were no statistically significant differences between individuals with GG and individuals with GA regarding glycemic profile (FBG, 2 hours post prandial blood glucose and HbA1c), HOMA-IR and lipid profile (total cholesterol, triglycerides, LDL-C, and HDL-C) $(\mathrm{p}>0.05)$ as shown in table (4).

Table (1): Comparison between groups regarding demographic, Clinical and laboratory characteristics

\begin{tabular}{|c|c|c|c|c|c|}
\hline \multirow{2}{*}{ Variables } & \multicolumn{2}{|c|}{$\begin{array}{c}\text { Patient } \\
n=60\end{array}$} & \multicolumn{2}{|c|}{$\begin{array}{c}\text { Control } \\
\mathrm{n}=40\end{array}$} & \multirow{2}{*}{ P-value } \\
\hline & Mean \pm SD & $\begin{array}{c}\text { Median } \\
\text { (IQR) }\end{array}$ & Mean \pm SD & $\begin{array}{c}\text { Median } \\
\text { (IQR) }\end{array}$ & \\
\hline Age in years & $50.26 \pm 9.1$ & $\begin{array}{c}49.5 \\
(42.5-55)\end{array}$ & $49.5 \pm 5.99$ & $\begin{array}{c}48 \\
(46.25-52)\end{array}$ & 0.719 \\
\hline $\mathrm{SBP}(\mathrm{mmHg})$ & $130.6 \pm 6.4$ & $\begin{array}{c}130 \\
(130-132.5)\end{array}$ & $118.25 \pm 7.48$ & $\begin{array}{c}120 \\
(110-120)\end{array}$ & $<0.001$ \\
\hline $\mathrm{DBP}(\mathrm{mmHg})$ & $82 \pm 6.7$ & $\begin{array}{c}80 \\
(80-90) \\
\end{array}$ & $76.5 \pm 5.87$ & $\begin{array}{c}80 \\
(70-80) \\
\end{array}$ & 0.004 \\
\hline $\mathrm{WC}(\mathrm{cm})$ & $120.57 \pm 8.49$ & $\begin{array}{c}118 \\
(116-125) \\
\end{array}$ & $103.7 \pm 6.4$ & $\begin{array}{c}105 \\
(102-176.25) \\
\end{array}$ & $<0.001$ \\
\hline BMI $(\mathrm{Kg} / \mathrm{cm} 2)$ & $38.86 \pm 7.2$ & 37.87 & $27.63 \pm 1.3$ & 25.83 & $<0.001$ \\
\hline FBG (mg/dl) & $171.17 \pm 7.6$ & 145.5 & $81.15 \pm 4.58$ & 82 & $<0.001$ \\
\hline 2hPP (mg/dl) & $235.13 \pm 2.4$ & 234 & $95.7 \pm 4.49$ & 95.5 & $<0.001$ \\
\hline $\mathrm{HbA1c} \%$ & $8.87 \pm 1.25$ & 8.05 & $5.705 \pm 0.24$ & 5.8 & $<0.001$ \\
\hline $\begin{array}{c}\text { Total } \\
\text { Cholesterol } \\
(\mathrm{mg} / \mathrm{dl})\end{array}$ & $172.43 \pm 8.42$ & 171 & $129.1 \pm 8.35$ & 131.5 & $<0.001$ \\
\hline $\begin{array}{l}\text { Triglycerides } \\
(\mathrm{mg} / \mathrm{dl})\end{array}$ & $154.23 \pm 4.22$ & 157.5 & $115.1 \pm 8.7$ & 112.5 & $<0.001$ \\
\hline LDL-C & $71.7 \pm 3.8$ & 65 & $51.3 \pm 8.24$ & 50 & $<0.001$ \\
\hline HDL-C & $45.2 \pm 2.7$ & 45 & $53.7 \pm 4.7$ & 55 & 0.003 \\
\hline
\end{tabular}

*Data are presented as mean $\pm \mathrm{SD}$, median (IQR), or number.

Table (2): Comparison between studied groups regarding Genotype data

\begin{tabular}{|c|c|c|c|c|}
\hline \multicolumn{2}{|c|}{ Variables } & Patient n= 60 & Control n=40 & \multirow{2}{*|}{ P-value } \\
\hline \multirow{2}{*}{ HSD11及1 } & GG & $46(76.7 \%)$ & $34(85 \%)$ & $\mathbf{0 . 4 4 7}$ \\
\cline { 2 - 4 } & GA & $14(23.3 \%)$ & $6(15 \%)$ & \\
\hline
\end{tabular}

*Data are presented as number (\%). HSD11ß1: Hydroxysteroid 11-Beta Dehydrogenase 1 
Table (3): Association analysis of all patients included in the study $(n=60)$ and control $(n=40)$ regarding Genotype data

\begin{tabular}{|c|c|c|c|}
\hline Variables & Odds Ratio & $\mathbf{9 5 \%}$ CI & P-value \\
\hline HSD11及1 polymorphism & 1.7246 & $0.601-4.94$ & $\mathbf{0 . 4 4 7}$ \\
\hline
\end{tabular}

*Data are presented as mean $\pm \mathrm{SD}$, median (IQR), or number (\%). HSD11ß1: Hydroxysteroid 11-Beta Dehydrogenase 1; OR: Odds ratio

Table (4): Comparison between $\mathrm{GG}(\mathrm{n}=80)$ and GA $(\mathrm{n}=20)$ patients regarding demographic, clinical and laboratory data

\begin{tabular}{|c|c|c|c|c|c|}
\hline \multirow{2}{*}{ Variables } & \multicolumn{2}{|c|}{ GG $n=80$} & \multicolumn{2}{|c|}{ GA $n=20$} & \multirow{2}{*}{ P-value } \\
\hline & Mean \pm SD & Median (IQR) & Mean \pm SD & Median (IQR) & \\
\hline Age in years & $49.18 \pm 7.1$ & 48 & $52.42 \pm 10.4$ & 50 & 0.257 \\
\hline \multirow{2}{*}{ Sex } & Male & $38(47.5 \%)$ & $8(40 \%)$ & & \multirow{2}{*}{0.252} \\
\hline & Female & $42(52.5 \%)$ & $12(60 \%)$ & & \\
\hline $\mathrm{SBP}(\mathrm{mmHg})$ & $125.06 \pm 6.4$ & 130 & $127.14 \pm 10.6$ & 130 & 0.259 \\
\hline $\mathrm{DBP}(\mathrm{mmHg})$ & $\begin{array}{l}79.87 \\
\pm 6.6\end{array}$ & 80 & $79.52 \pm 7.4$ & 80 & 0.892 \\
\hline $\mathrm{BMI}\left(\mathrm{Kg} / \mathrm{cm}^{2}\right)$ & $34.35 \pm 1.1$ & 33.29 & $34.1 \pm 1.3$ & 35.15 & 0.93 \\
\hline $\mathrm{WC}(\mathrm{cm})$ & $114.35 \pm 11.3$ & 115 & $111.62 \pm 12.7$ & 117 & 0.532 \\
\hline $\mathrm{FBG}(\mathrm{mg} / \mathrm{dl})$ & $129.9 \pm 9.5$ & 103 & $150.48 \pm 8.6$ & 120 & 0.461 \\
\hline $2 \mathrm{hPP}(\mathrm{mg} / \mathrm{dl})$ & $173.84 \pm 9.6$ & 125 & $196.24 \pm 14.5$ & 155 & 0.386 \\
\hline $\mathrm{HbA} 1 \mathrm{c} \%$ & $7.45 \pm 1.14$ & 6 & $7.94 \pm 1.7$ & 7.5 & 0.459 \\
\hline HOMA-IR & $3.4 \pm 0.1$ & 3.2 & $3.3 \pm 0.4$ & 3.1 & 0.571 \\
\hline $\begin{array}{c}\text { Cholesterol } \\
(\mathrm{mg} / \mathrm{dl})\end{array}$ & $155.66 \pm 8.9$ & 140 & $129.1 \pm 8.35$ & 131.5 & 0.642 \\
\hline $\mathrm{TG}(\mathrm{mg} / \mathrm{dl})$ & $138.26 \pm 33.5$ & 128 & $115.1 \pm 8.7$ & 112.5 & 0.808 \\
\hline LDL & $65.47 \pm 9.2$ & 52 & $51.3 \pm 8.24$ & 50 & 0.238 \\
\hline HDL & $48.64 \pm 5.4$ & 47 & $53.7 \pm 4.7$ & 55 & 0.945 \\
\hline
\end{tabular}

*Data are presented as mean $\pm \mathrm{SD}$, median (IQR), or number (\%). 


\section{DISCUSSION}

The prevalence of DM has been growing all over the world throughout recent decades and the trend is set to progress as a consequence of population aging, urbanization, and associated lifestyle changes. In 2019, the number of deaths caused by diabetes and its complications is estimated to be 4.2 million and the annual global health expenditure on diabetes is estimated to be USD 760 billion and expected to reach USD 825 billion by 2030 worldwide ${ }^{(\mathbf{1})}$. T2DM, which accounts for the vast majority of diabetes cases, is a multifactorial disease with a strong genetic basis, with heritability estimates ranging from 30 to $70 \%{ }^{(8,9)}$. Thousands of germline genetic loci estimated to contribute to disease, including more than 200 that have been identified to date ${ }^{(\mathbf{1 0})}$.

Overexpression of HSD11 1 involved in the interconversion of inert cortisone and active cortisol in metabolically active tissues, and is associated with insulin resistance, metabolic syndrome, T2DM and hypertension. The role of single-nucleotide polymorphisms (SNPs) of the HSD11B1 gene in the susceptibility to metabolic syndrome and T2DM has been reported (11). However, the established association between HSD11 $\beta 1$ gene (rs846910) polymorphism and the risk of T2DM is still unclear.

This study showed that there was no statistically significant difference between cases and controls in terms of HSD11 $\beta 1$ polymorphism (rs846910). The regression analysis showed that the HSD11ß1 polymorphism did not significantly increase the risk of DM (OR 1.724, 95\% CI (0.601 4.94)). Moreover, there were no statistically significant differences between individuals with GG and individuals with GA in terms of SPB, DBP, WC, BMI, glycemic profile (FBG, $2 \mathrm{Hpp}$ and $\mathrm{HbA1c}$ ), HOMA-IR and lipid profile (total cholesterol, triglycerides, LDL-C, and HDL-C) ( $\mathrm{p}>0.05)$. In concordance with our findings, a systematic review was conducted to evaluate the association of HSD11 11 gene expression in abdominal adipose tissue and HSD11B1 polymorphisms with T2DM. The authors reported that most of the included studies showed no significant associations between HSD11B1 polymorphisms and T2DM (12). The association between HSD11 $\beta 1$ polymorphisms and T2DM and metabolic phenotypes was studied in Koreans. The results showed no association between common polymorphisms of HSD11B1 and T2DM ${ }^{(13)}$. Correspondingly, the correlation of common SNPs in HSD11ß1 (rs12086634), (rs1000283) and H6PD (rs6688832), (rs17368528) with T2DM and metabolic syndrome were studied in Korean research and no substantial link of these SNPs with T2DM and metabolic syndrome was found ${ }^{(14)}$. Moreover, the association of HSD11 $\beta 1$ gene variants with diabetes, hypertension, and obesity was examined in a longitudinal population study of American Indians $(\mathrm{N}=918)$. The results showed that the associations between HSD11 $\beta 1$ gene variants with diabetes were not statistically significant ${ }^{(15)}$.

On the contrary, the association of HSD11 1 (rs12086634 and rs846910) gene polymorphisms were assessed with T2DM. A total of 616 subjects were enrolled. The association analysis indicated that HSD11 11 rs12086634 TG and HSD11 $\beta 1$ rs846910 AG contributed to an increased risk of T2DM (16). Similarly, genetic association studies in Pima Indians were done to study the association between HSD $11 \beta 1$ gene polymorphisms with T2DM. The results showed that the genetic variations in the HSD11B1 gene were associated with T2DM, plasma insulin concentrations, and insulin action ${ }^{(\mathbf{6})}$.

The exact causes of such heterogeneity in the published literature, regarding the association between HSD1 $1 \beta 1$ gene polymorphisms with T2DM, are unclear. However, this difference can be attributed to many methodological differences. Different populations, whether healthy subjects or T2DM patients, were included in the above-mentioned studies. Moreover, the type of polymorphism was substantially different among the published studies. Another explanation is the differences in sample size.

The limitations of our study were the small sample size, which may be not sufficient to detect association between the SNP (rs846910) polymorphism and type 2 diabetes. Second, rs846910 polymorphism was the only screened singlenucleotide polymorphism (SNP) for evaluation of the relationship between HSD11ß1gene polymorphism and T2DM while other SNPs may have strong associations with diabetes or metabolic syndrome in Egyptian population. Therefore, the probability of a positive association between HSD11 $\beta 1$ gene polymorphism and diabetes remains.

\section{CONCLUSION}

The present study showed no significant association between HSD11 $\beta 1$ polymorphism (rs846910) and T2DM. The HSD11 $\beta 1$ polymorphism did not significantly increase the risk of diabetes mellitus in obese individuals.

\section{List of Abbreviations:}

HSD1 1 $\beta 1$ : 11beta-hydroxysteroid dehydrogenase Type 1

SNP: single-nucleotide polymorphism

DBP: Systolic blood pressure

DBP: Diastolic blood pressure

WC: Waist circumference

BMI: Body mass index

FBG: Fasting blood glucose

HbA1c: Glycated hemoglobin 
HOMA-IR: Homeostatic model assessment-insulin resistance

TG: Triglyceride; LDL: Low-density lipoprotein;

HDL: High-density lipoprotein

T2DM: type 2 diabetes mellitus

DM: Diabetes Mellitus.

\section{REFERENCES}

1. International Diabetes Federation (2019): Diabetes Atlas, 9th edn. Brussels, Belgium. https://www.diabetesatlas.org

2. American Diabetes Association (2020): Classification and Diagnosis of Diabetes: Standards of Medical Care in Diabetes-2020. Diabetes Care, 43 (1): 14-31. https://doi.org/10.4049

3. Pyke D (1979): Diabetes: The genetic connections. Diabetologia, 17: 333-343.

4. Lyssenko V, Lupi R, Marchetti $P$ et al. (2007): Mechanisms by which common variants in the TCF7L2 gene increase risk of type 2 diabetes. The Journal of clinical investigation, 117 (8): 2155-2163.

5. Thieringer $R$, Le Grand $C$, Carbin $L$ et al. (2001): 11ß-Hydroxysteroid dehydrogenase type 1 is induced in human monocytes upon differentiation to macrophages. The Journal of Immunology, 167 (1): 30-35.

6. Nair S, Lee $\mathbf{Y}$, Lindsay $\mathbf{R}$ et al. (2004): 11ßHydroxysteroid dehydrogenase Type 1: genetic polymorphisms are associated with Type 2 diabetes in Pima Indians independently of obesity and expression in adipocyte and muscle. Diabetologia, 47 (6): 10881095.

7. Dujic T, Ostanek B, Marc J et al. (2011): Optimization of High-Resolution Melting Analysis for Simultaneous Genotyping of Two 11 $\beta$-Hydroxysteroid Dehydrogenase Type 1 Gene Polymorphisms. Genetic Testing and Molecular Biomarkers, 15 (1-2): 43-49.

8. Willemsen G, Ward K, Bell $\mathbf{C}$ et al. (2015): The concordance and heritability of type 2 diabetes in 34,166 twin pairs from international twin registers: the discordant twin (DISCOTWIN) consortium. Twin Research and Human Genetics, 18 (6): 762-771.

9. Almgren P, Lehtovirta M, Isomaa $B$ et al. (2011): Heritability and familiarity of type 2 diabetes and related quantitative traits in the Botnia Study. Diabetologia, 54 (11): 2811-6.

10. Mahajan A, Taliun D, Thurner M et al. (2018): Finemapping type 2 diabetes loci to single-variant resolution using high-density imputation and islet-specific epigenome maps. Nat Genet., 50 (11): 1505-13.

11. Devang N, Nandini M, Rao S et al. (2016): HSD11B1 gene polymorphisms in type 2 diabetes and metabolic syndrome-Do we have evidence for the association? International Journal of Diabetes in Developing Countries, 36 (1): 95-102.

12. Do Nascimento F, Piccoli V, Beer $M$ et al. (2015): Association of HSD11B1 polymorphic variants and adipose tissue gene expression with metabolic syndrome, obesity, and type 2 diabetes mellitus: a systematic review. Diabetology \& Metabolic Syndrome, 7 (1): 38-43.

13. Ku Y, Koo B, Kwak S et al. (2009): Regulatory effect of common promoter polymorphisms on the expression of the 11ß-hydroxysteroid dehydrogenase type 1 gene. Hormone Research in Paediatrics, 72 (1): 25-32.

14. Moon S, Lee Y, Kim J et al. (2011): Relationship of $11 \beta$-hydroxysteroid dehydrogenase type 1 and hexose6-phosphate dehydro-genase gene polymorphisms with metabolic syndrome and type 2 diabetes. https://doi.org/10.1507/endocrj.EJ11-0035

15. Franks $P$, Knowler W, Nair $S$ et al. (2004): Interaction between an 11ßHSD1 gene variant and birth era modifies the risk of hy-pertension in Pima Indians. Hypertension, 44 (5): 681-688.

16. Devang N, Satyamoorthy K, Rai $P$ et al. (2017): Association of HSD11B1 gene polymorphisms with type 2 diabetes and metabolic syndrome in South Indian population. Diabetes Research and Clinical Practice, 131: 142-148. 